\title{
Guidelines for the Treatment of Head Injury in Adults
}

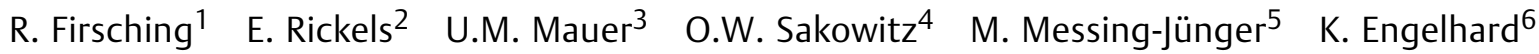 \\ $\begin{array}{lll}\text { P. Schwenkreis } & \text { J. } \text { Linn }^{8} \quad \text { K. Schwerdtfeger } & \\ & \text {,** }\end{array}$
}

${ }^{1}$ Klinik für Neurochirurgie, Magdeburg, Germany

2 Neurochirurg, Med. Versorgungszentrum am AKH Celle, Celle, Germany

${ }^{3}$ Neurochirurgischen Klinik, Bundeswehrkrankenhaus Ulm, Ulm,

Germany

${ }^{4}$ Neurochirurgischen Klinik, Neurochirurgische Universitätsklinik,

Heidelberg, Germany

${ }^{5}$ Chefärztin Kinderneurochirurgie, Asklepios Klinik Sankt Augustin, Germany

${ }^{6}$ Klinik für Anästhesiologie, Universitätsmedizin der Johannes Gutenberg-Universität Mainz, Mainz, Germany

${ }^{7}$ Neurologische Universitätsklinik und Poliklinik, Berufsgenossenschaftliches Universitätsklinikum Bergmannsheil, Bochum, Germany

8 Ärztliche Direktorin Institut und Poliklinik für Neuroradiologie, Universitätsklinikum Carl Gustav Carus Dresden an der Technischen Universität Dresden, Anstalt des öffentlichen Rechts des Freistaates

Sachsen, Dresden, Germany

${ }^{9}$ Klinik Universitätsklinikum des Saarlandes, Klinik für

Neurochirurgie, Homburg/Saar, Germany

J Neurol Surg A 2017;78:478-487.
Address for correspondence Prof. Dr. med. R. Firsching, Klinik für Neurochirurgie, Leipziger Str. 44, Magdeburg 39120, Germany (e-mail: Raimund.Firsching@medizin.uni-magdeburg.de).

\begin{abstract}
Keywords

- head injury

- guidelines

- adults

The workshop of scientific medical faculties (Arbeitsgemeinschaft wissenschaftlicher medizinischer Fakultäten [AWMF]) of Germany has asked societies of specific medical disciplines to jointly publish guidelines on the treatment of diseases and injuries. On behalf of the Deutsche Gesellschaft für Neurochirurgie, its commission on guidelines initiated an interdisciplinary approach to publish guidelines on the treatment of head injury in adults. These guidelines were published in German by the AWMF in late 2015. Because these guidelines have received widespread attention in Germany and became fundamental for research in head injuries, we have translated the German version into English to make it accessible to the international scientific community.
\end{abstract}

\section{Introduction}

Head injury is the most frequent cause of death up to early adulthood. Because brain tissue has the shortest tolerance to hypoxia of all organs, urgent treatment is required to maximize survival and to minimize permanent brain damage in survivors.

These guidelines are designed to outline the current methods of diagnosis and care for patients with head injury at the site of the accident, during transport, and at the hospital. They

received

November 20, 2016

accepted after revision

November 22, 2016

published online

May 8, 2017

are aimed at anyone treating patients with head injuries. Basic medical knowledge, however, is a prerequisite.

The basis of these guidelines is the grade of evidence as published in the scientific literature. This evidence is classified into five grades. ${ }^{1}$

Three levels of recommendation, A, B, or 0 , are based on these grades of evidence of statements according to the national program of guidelines of medical service. ${ }^{2}$

The definition of these levels of recommendation is $\mathrm{A}$, strong recommendation; $\mathrm{B}$, recommendation; and 0 , recommendation uncertain.

(c) 2017 Georg Thieme Verlag KG Stuttgart · New York
DOI https://doi.org/ 10.1055/s-0037-1599239. ISSN 2193-6315. 
Table 1 Therapeutic studies

\begin{tabular}{|l|l|l|}
\hline $\begin{array}{l}\text { Level of } \\
\text { recommendation }\end{array}$ & $\begin{array}{l}\text { Grade of } \\
\text { evidence }\end{array}$ & Type of study \\
\hline $\mathrm{A}$ & $1 \mathrm{a}$ & Systemic review of randomized controlled studies \\
\hline & $1 \mathrm{~b}$ & Minimum of one randomized controlled study \\
\hline $\mathrm{B}$ & $2 \mathrm{a}, \mathrm{b}$ & Systematic review of comparing cohort studies \\
\hline & $3 \mathrm{a}, \mathrm{b}$ & $\begin{array}{l}\text { Systematic review of case-controlled studies or at } \\
\text { least one adequate controlled study }\end{array}$ \\
\hline 0 & 4 & $\begin{array}{l}\text { Case series and inadequate case-controlled studies } \\
\text { justified expert opinion }\end{array}$ \\
\hline & 5 & Opinion without critical appraisal \\
\hline
\end{tabular}

The authors developing these guidelines reached a consensus attributing the respective level of recommendation. In some cases the grade of evidence and the level of recommendation did not coincide when an excessively high degree of certainty was considered evident. Accordingly, the surgical measures in intracranial space-occupying hematomas were attributed a high level of recommendation in the absence of appropriate clinical studies. For decades, respective observations of their efficacy have never been questioned but confirmed by everyday experience and good clinical practice. Most of the recommendations are classified according to the subsequent grades of evidence ${ }^{1}$ (- Tables 1 and $\mathbf{2}$ ).

\section{Definition}

A head injury is caused by the effect of force to the head that may have caused a dysfunction of the brain and in addition may have led to an injury of the brain, scalp, skull bone, vessels, and dura.

An open head injury involves a laceration of the dura and soft tissue leading to open access of the subdural space to the outside.

Primary brain injury is a lesion caused by the initial effect of force leading to reversible or irreversible dysfunction of brain cells. These primary lesions, however, can lead to a cascade of reactions causing delayed secondary brain injuries, which may be prevented by urgent and effective measures that are the object of medical and other treatment of head injuries.

\section{Epidemiology}

In Germany there are $~ 332$ head injuries per 100,000 inhabitants. Of these, $91 \%$ are classified as mild, $4 \%$ are moderate, and $5 \%$ are severe. Altogether $\sim 280,000$ patients experienced a head injury, of whom 2,750 die. The overall cost for society has been estimated to reach $€ 2.8$ billion per year. ${ }^{3}$

\section{Symptoms and Signs}

Symptoms after head injury are headache, dizziness, sickness, diplopia, deafness, and amnesia. Signs after head injury are bruises, laceration of scalp, deformities of the skull, bleeding from the scalp, mouth, nose, and/or ear. Further signs raising suspicion of a head injury are decreased wakefulness, vomiting, seizures, posturing, disorder of orientation, speech, and/or coordination, cranial nerve function, and/or vegetative or motor function. A disorder of

Table 2 Diagnostic studies

\begin{tabular}{|l|l|l|}
\hline $\begin{array}{l}\text { Level of } \\
\text { recommendation }\end{array}$ & $\begin{array}{l}\text { Grade of } \\
\text { evidence }\end{array}$ & Type of study \\
\hline $\mathrm{A}$ & $1 \mathrm{a}$ & Systematic review of adequate studies type Ib \\
\hline $\mathrm{B}$ & $1 \mathrm{~b}$ & $\begin{array}{l}\text { Double-blind objective independent randomized } \\
\text { study involving all subjects of target group }\end{array}$ \\
\hline & $2 \mathrm{a}, \mathrm{b}$ & $\begin{array}{l}\text { Systematic review of diagnostic study or at least one } \\
\text { selective randomized study with independent blinded } \\
\text { and objective reference test of target population }\end{array}$ \\
\hline 0 & $3 \mathrm{a}, \mathrm{b}$ & $\begin{array}{l}\text { Systematic review of diagnostic studies or at least } \\
\text { one study without inclusion of all patients in the } \\
\text { reference test }\end{array}$ \\
\hline & 4 & $\begin{array}{l}\text { Case-controlled study or studies without independent } \\
\text { blinded or objective reference test }\end{array}$ \\
\hline
\end{tabular}


consciousness indicates a serious dysfunction of the brain. Full consciousness may be differentiated from impaired consciousness and unconsciousness.

Impaired consciousness includes reduced wakefulness, disorder or absence of orientation in terms of time, place, and self-awareness. Eyes can be open.

Unconsciousness (synonymous with coma): Absence of awareness of surroundings and self. The clinical signs are a nonarousable state, the patient does not open eyes spontaneously or on painful stimuli and does not follow commands. Movements upon painful stimuli or spontaneously are possible. A Glasgow Coma Scale (GCS) score $<8$ represents coma. Clinical signs of a life-threatening deterioration of patients with impaired consciousness or coma are the loss of pupillary function, hemiparesis, acute circulatory disorders, and extensor response. ${ }^{4-9}$

\section{Classification of the Severity of Head Injury}

Head injury is a dynamic disorder in the acute phase. Because rapid deterioration or improvement is common, the original assessment of the injury must be adjusted to the clinical course of events.

An internationally most frequently used classification is the differentiation of three grades of minor, moderate, and severe head injury according to the sum score of the GCS. The point in time of when the GCS is recorded (e.g., time of admittance to the hospital, site of accident, the least favorable score within the first 48 hours) has not been defined uniformly. In addition to the methodological weaknesses of the GCS sum score, the reliability and the validity of this classification has been viewed with reservations.

The severity of the head injury is of secondary relevance for the actual treatment, which is governed by the actual neurologic findings and the course of events, particularly in the early phase of the course that requires frequent repeat investigations. ${ }^{10-17}$

A classification popular in Germany by Tönnis and Loew ${ }^{17}$ suggested three degrees of severity based on the duration of persisting neurologic disorders and may therefore only be applied retrospectively.

\section{Additional Injuries of the Patient with Head Injury}

Additional life-threatening injuries must be suspected in any comatose patient after a head injury. The search for multiple injuries is urgent and often difficult because the comatose patient will not be able to talk or understand or indicate the location where he or she is in pain. Particularly disorders of respiratory function and/or severe external or internal blood loss need urgent attention because they may lead to cerebral hypoxia and increase cerebral lesions.

Approximately $15 \%$ of patients with severe head injuries suffer additional spinal injuries. Unless proven otherwise, any comatose patient should therefore be suspected to have an additional spinal injury.

In addition to the head injury, there may also be injuries of cerebral vessels, such as dissection of arteries, traumatic aneurysms, and arteriovenous fistula.

\section{First Aid at the Site of Accident: Preclinical Care}

\section{Urgent Treatment}

An unfavorable outcome after head injury is related to hypoxia and arterial hypotension. Any measures to counteract hypoxia or hypotension have absolute priority. Because spontaneous respiration may become inadequate any time after a brain injury, preventive measures to ensure adequate oxygen supply of the brain are urgent.

\section{A}

Patients in a coma (GCS of 8 or lower) are to be intubated. Disorders of respiration, pneumothorax, and hematothorax are to be treated urgently. ${ }^{18}$

B

Normal oxygenation and normocapnia are desirable. Arterial oxygen saturation should not drop $<90 \%$ if possible. Obvious hemorrhage must be stopped to ensure adequate cardiovascular function. Blood pressure and pulse rate should be monitored and lost fluids substituted. B

Normal blood pressure is desirable; a blood pressure $<90$ $\mathrm{mm} \mathrm{Hg}$ is to be avoided. ${ }^{19-20}$

\section{History}

A

In addition to the neurologic findings, the medical history of the patient is essential because it may offer clues indicating an intracranial injury. It is essential to record the history of the patient. Details on the type of damage to the car or the height of the fall either from the patient or from a bystander may indicate the type and direction of force suffered at the time of injury and may be relevant to the management of the patient. Information on current medication (e.g., anticoagulation) of the patient or drug abuse is also important.

\section{Neurologic Examination}

The assessment and documentation of the following is considered essential:

A

- Full consciousness, impaired consciousness, unconsciousness

- Function of pupils ${ }^{11,12}$

- Motor function of each arm and leg, differentiating no, partial, and complete paralysis. Without spontaneous movements, motor function upon painful stimuli must be tested. Special attention should be directed to hemiparesis and flexor or extensor response.

When the patient is not unconscious, the recording of orientation, function of cranial nerves, speech, and coordination is mandatory.

All these essential neurologic findings must be documented with the corresponding time. They govern the subsequent management. 
B

Short-term repeat examinations are advisable to detect any deterioration.

B

The neurologic findings should be registered in a standardized fashion. The GCS has been accepted internationally. The limitations of this scale, misleading signs of improvement, limitations in intubated and sedated patients, and so on, must be considered.

The GCS has been widely used to describe and encode a disorder of brain function. In spite of its universal application, difficulties have been reported. The GCS is a standardized classification of three phenomena: eye opening, verbal communication, and best motor function of arms. Its use may lead to misjudgments because the signs differentiating a deterioration of prognosis in coma are limited to the best motor function. Thus the most important signs of acute life-threatening herniation in coma, loss of pupil function, hemiparesis, and the unconditional registration of flexor or extensor response, are not discerned with the GCS. The sum score of the GCS may therefore be misleading. It is clearly inferior to a detailed neurologic investigation. ${ }^{10-12,16,21}$

\section{Head Injury Caused by a Disorder of Consciousness of Nonrelated Origin}

An acute onset of impaired consciousness from various causes may precipitate head injury. A disturbance of blood glucose is easy to detect and treat. Coma may be of endocrine, metabolic, cardiovascular, cerebrovascular, or other origin (e.g., intoxication or hypothermia). ${ }^{11}$

\section{Indication for In-Hospital Treatment}

With any of the subsequent signs the patient should be admitted to the hospital:

A

- Coma

- Impaired consciousness

- Amnesia

- Other neurologic signs

- Seizures

- Clinical or radiologic signs of skull fracture or penetrating injury, suspected nasal or petrous bone cerebrospinal fluid (CSF) fistula

In any of the subsequent clinical signs a referral to a hospital appears advisable:

B

- Vomiting in close temporal relationship to the injury

- Evidence of a disorder of coagulation

- If in doubt

\section{A}

The choice of hospital depends on the time necessary to reach it and on the facilities it offers. Patients comatose after head injury or with deteriorating con- sciousness, disorder of pupil function, paresis, or seizures should be transported to an institution with constantly available neurosurgical care. ${ }^{11}$

\section{Transport}

Neither analgesia, sedation, nor relaxation may be recommended because there is no adequate evidence in the literature to confirm any benefit. Although some patients may require analgesia or sedation to ensure adequate respiration, it may be at the expense of the realization of clinical signs of deterioration.

The perforating object should not be removed if possible in transfixing injuries. An additional spinal injury should be suspected in any comatose patient. During transportation a stiff collar to protect the cervical spine and respective caution is recommended until appropriate diagnostic measures can be taken. ${ }^{12}$

\section{Measures to Protect the Brain}

\section{A} Glucocorticoids should not be given because an increased 14-day mortality has been reported. ${ }^{22}$

\section{0}

Mannitol or hyperosmolar saline can lower the intracranial pressure (ICP) for a short time (up to 1 hour). It can be recommended when transtentorial herniation is suspected even without verification of increased ICP. There is no evidence beyond this indication. ${ }^{19}$

o

Hyperventilation may be an option with signs of transtentorial herniation, anisocoria posturing, and deterioration of consciousness. Twenty breathing cycles per minutes in adults appear adequate.

o

Barbiturates have been recommended in noncontrollable ICP in earlier guidelines. However, there is no sufficient evidence for its effectiveness. Barbiturates are administered at the expense of monitoring of neurologic findings. They have a negative inotropic side effect and can possibly cause a detrimental drop in blood pressure.

B

Anticonvulsive agents inhibit seizures in the first week after injury. Early seizures, however, have no effect on long-term outcome. ${ }^{23}$

From clinical studies there is no evidence of the protective effect of any further drugs that have been considered effective in experimental studies, such as 21-aminosteroids, calcium antagonists, glutamate receptor antagonists, and so on. ${ }^{11,12,19,22-23}$

\section{Documentation}

\section{A}

Details of the mechanism of the injury and the initial examination and follow-up of neurologic 
findings are fundamental. These findings should be documented.

\section{First Aid after Hospital Admission}

Because a comatose patient after a head injury may have suffered multiple injuries, a multidisciplinary team should await the patient in the emergency department.

After ensuring vital functions, resuscitation, and recording of the clinical findings diagnostic imaging is urgent. Identification of bleeding into the major cavities of the body, skull, thorax, or abdomen has priority over the diagnosis of nonvital injuries. In comatose patients, life-threatening injuries must be suspected not only in the head because they may be multiple and anywhere. Hints to facilitate their diagnosis are obtained from the history and mechanism of the injury and the first clinical findings.

\section{Imaging after Head Injury}

Computed tomography (CT) is currently considered the gold standard in patients who have suffered a head injury. CT after acute head injury is necessary, an absolute indication, in:

A

- Coma

- Impaired consciousness

- Amnesia

- Other neurologic disorders

- Vomiting in close temporal relation to the injury

- Seizure

- Clinical or radiologic signs of skull fracture

- Suspected depressed or perforating skull fracture

- Suspected CSF fistula

- Signs of a disorder of coagulation (history, prolonged bleedings, etc.)

- When in doubt, CT is optional, for example, in:

B

- History of head injury unclear

- Severe headache

- Intoxication with alcohol or drugs

B

- History of a high-energy injury such as motor vehicle accident of $>60 \mathrm{~km} /$ hour, deformation of the vehicle, deformation of the passenger cabin of $>30 \mathrm{~cm}$, duration of rescue from the vehicle of $>20$ minutes, fall from height higher than $6 \mathrm{~m}$, rolled-over injury, pedestrian or motorcycle collision of $>30 \mathrm{~km} /$ hour, cyclist knocked off the cycle. $^{34}$

Because the instant removal of an intracranial hemorrhage may be lifesaving, there is no justification to delay urgent cranial CT scanning as long as cardiovascular and breathing functions are stable. This is equally relevant for the initially noncomatose patient who was sedated and intubated prior to transportation, in whom a developing intracranial hemorrhage can be differentiated from the effect of medication only with CT. The current fastest and most efficient imaging technique in multiple injuries is a spiral CT of the head, thorax, and abdomen. After diagnosis or exclusion of acutely life-threatening injuries, further diagnostic procedures may focus on injuries of bone and other nonimmediate life-threatening injuries.

When the indication for CT is optional, close monitoring of neurologic findings is another option. A cranial CT may not be necessary with serum S100 levels $<0.14 \mu \mathrm{g}$ / L. ${ }^{35}$ In a case where CT is not available, the patient should be referred to a hospital with neurosurgical expertise when a fracture is identified with conventional radiography. The absence of a skull fracture, however, does not rule out intracranial hemorrhage.

$\mathrm{CT}$, respectively repeat $\mathrm{CT}$, is also necessary in deterioration of neurologic findings or when the patient fails to recover or is in a persisting coma after 4 to 8 hours. $^{34-37}$

\section{Magnetic Resonance Imaging}

Magnetic resonance imaging (MRI) is usually not feasible in acute injuries in terms of availability and time. ${ }^{38}$ It is, however, far superior to $\mathrm{CT}$ in detecting lesions of brain tissue and is particularly recommended when CT offers no explanation for neurologic deficits. ${ }^{39}$

\section{Indication for Admission to Hospital}

Admission to hospital is indicated in:

A

- Lesions requiring surgical treatment

- Disorder of consciousness, coma

- Neurologic deficits

- Skull fracture

- CSF leakage, open head injury

- Lesions depicted by CT

In addition, admission to hospital may be advisable in:

B

- Additional disorders requiring treatment

- Severe headache, vertigo, intoxication with drugs or alcohol

\section{Therapy}

The purpose of treatment after head injury is to limit secondary brain lesions and support recovery of lost function. Lesions in urgent need of operation should be identified promptly.

Therapy begins with first aid at the site of accident and is continued in the hospital.

\section{Emergency Surgery}

The indication for surgical removal of a traumatic space-occupying lesion has never been confirmed in a 
prospective randomized controlled study. Several retrospective analyses have confirmed the benefit of surgical decompression. In keeping with unchallenged experiences for many decades, the surgical removal of space-occupying traumatic intracranial lesions can be viewed as good clinical practice and has never been questioned. ${ }^{40-42}$

\section{A}

Space-occupying intracranial lesion is an absolute indication for urgent surgical removal. This applies to traumatic intracranial hemorrhages (extradural, subdural, or intracerebral hematomas) and space-occupying depressed skull fractures. The degree of space occupancy is defined by the displacement of midline structures, particularly the third ventricle. In addition to the degree of midline shift, location of hematoma, and volume of hematoma, the neurologic findings determine the indication and urgency of surgery. The outcome may depend on minutes when neurologic signs of transtentorial herniation develop.

\section{Operation with Delayed Urgency}

\section{B}

Open or closed depressed fractures without midline shift, perforating injuries, and basal fractures with CSF leakage may be considered in need of neurosurgery of delayed urgency. The timing of the operation may depend on many factors and must be determined by the neurosurgeon.

\section{B}

Nonvital operations of concomitant injuries in the comatose patient should only be performed as far as they are necessary to ensure adequate intensive care. Operations with significant loss of blood or volume shift should be avoided. Principles of "damage control surgery" have been suggested. Further operations should be delayed until the state of the patient appears adequately stable. ${ }^{14,42,43}$

\section{Decompressive Craniectomy}

\section{$\mathbf{0}$}

Decompressive craniectomy and duraplasty is the most powerful option to lower increased ICP. Mostly the indication becomes apparent with increasing brain edema often some days after the injury, in some cases immediately after the accident due to swelling. Some studies have reported good results, but this procedure is still an object of research. ${ }^{44-46}$

\section{Nonoperative Management of Intracranial Hematomas}

\section{$\mathbf{0}$}

Nonoperative management of intracranial hematomas may be warranted in certain cases when the neurologic findings remain stable. Neurosurgical evacuation must be readily available in case of deterioration or increasing volume of the hematoma. ${ }^{40}$

\section{Recording of Intracranial Pressure}

\section{B}

ICP has been recorded with increasing frequency in the acute management of comatose patients after head injury. The recording has been implemented in several national and international guidelines. For pathophysiologic reasons, the recording of ICP appears useful because the clinical monitoring of many cerebral functions is limited in the comatose and eventually sedated patient and may be an early warning of an impending herniation of the mesencephalon from swelling or intracranial hematomas and thus may allow for preventive measures in time.

To date there is no evidence from a prospective randomized controlled study that ICP monitoring has any effect on outcome. Several recent cohort studies and clinical practice, however, indicate its practical value in neurosurgical intensive care. The implementation of guidelines, which among others recommend ICP monitoring, has led to increasingly favorable outcomes of patients after a head injury. Neurosurgeons record ICP in comatose patients after a head injury after consideration of the clinical findings and imaging data to monitor and control ICP. The practical benefit for the patient from thus invasively obtained data is controversial, however, because the specific ICP level, which needs to be treated, has not been identified with scientific data, and the effect from medication, considered to have an ICP lowering effect, remains obscure. The overall benefit from ICP recording performed for pathophysiologic considerations must be weighed against its risk of complication. ${ }^{14,19,22,47-60}$

Sufficient perfusion of brain tissue requires adequate cerebral perfusion pressure (CPP), which is the difference of the mean arterial blood pressure and ICP. When the ICP is elevated, management remains uncertain from the evidence available in the literature. Should the ICP be lowered or should the CPP be elevated? The evidence available suggests:

B

- CPP should not drop below $50 \mathrm{~mm} \mathrm{Hg}^{19}$

B

- CPP should not be pushed above $70 \mathrm{~mm} \mathrm{Hg}^{19}$

B

- The continuous monitoring of CPP requires invasive recording of ICP. As long as there are no slit ventricles, ICP monitoring with ventricular drainage offers the option to withdraw CSF to lower ICP.

Simultaneous data on brain perfusion, oxygen saturation, and/or brain metabolism are required to determine the optimum CPP in the individual case. To define this value, regional recordings with parenchymal sensors, transcranial 
Doppler, and perfusion imaging are currently being investigated. $^{19,61,62}$

\section{Nonsurgical Management}

Patients after head injury require substitution of lost functions (respiration, nutrition). Current scientific data suggest achieving a state of homeostasis (normoxygenation, normotension, avoiding hyperthermia) and avoiding complications. Septicemia, pneumonia, and a disorder of coagulation are predictors of an unfavorable outcome.

In the absence of evidence for clinical benefit ensuring an adequate CPP, adequate brain perfusion is a fundamental pathophysiologic prerequisite of homeostasis. To ensure adequate CPP with increased ICP, a fall in blood pressure must be avoided, eventually requiring catecholamines. There are several options to lower increased ICP:

0

- Osmodiuretics (e.g., mannitol) may lower the ICP for a short time. ${ }^{19}$ Serum osmolality and kidney function must be monitored. There are no data to recommend administration of albumin.

$\mathbf{0}$

- Hyperventilation may transiently lower the ICP by vasoconstriction and thus decreased intracranial blood volume. The effect may be helpful in acute transtentorial herniation. Prolonged hyperventilation will lead to decreased brain perfusion and unfavorable results and should therefore be restricted to exceptional use.

$\mathbf{0}$

- Elevation of head and upper body to 30 degrees has been recommended, although it does not affect the CPP. Excessively high ICP, however, is reduced.

$\mathbf{0}$

- Analgesia/Sedation has no direct effect on ICP. In agitated patients with inadequate spontaneous respiration, sedation may enhance a lowering of ICP and ensure adequate oxygenation.

$\mathbf{0}$

- Hypertonic saline has been considered to have a brain-protective effect, but there is currently no adequate evidence.

$\mathbf{0}$

- Barbiturates had been recommended for the treatment of uncontrollably high ICP in earlier guidelines, but there is currently no sufficient evidence for this. The negative inotropic and hypotensive effects and the impossibility to monitor the neurologic state of the patient must be considered.

0

- Hyperbaric oxygen has not been demonstrated to be effective.

0

- Hypothermia has no proven beneficial effect. $\mathbf{0}$

- Hemostatic agents have no proven beneficial effect. Tranexamic acid may be considered an option.

$\mathbf{0}$

- Antibiotic prophylaxis in frontobasal fractures with CSF leakage has been controversial up to date. There is no evidence available to offer proof of its efficacy.

A

- Steroids after head injury have been controversial for many years. They should not be administered because they were associated with an increased 14day mortality after head injury.

B

- Anticonvulsants lower the likelihood of seizures in the first week after injury. An early seizure, however, does not have a bearing on clinical outcome. Anticonvulsants beyond the second week after head injury are not associated with a reduction of late seizures.

$\mathbf{0}$

- Prophylaxis of thrombosis with physical measures is not controversial to prevent secondary complications. Heparins and analogs bear the risk of additional hemorrhage and an increase of intracranial hematomas. Their benefit must be assessed in each individual case. Because they are not certified for the treatment of head injury, their off-label use is not possible without consent of the patient or the legal representative.

0

- Brain protection by medication: Several further agents (e.g., 21-aminosteroids, calcium antagonists, glutamate receptor antagonists, tris buffer) have been considered to have a brain-protective effect, but no scientific evidence is available for their benefit.

A

- Mydriatic agents are contraindicated in patients in posttraumatic coma because the onset of the loss of pupil reactivity as an early indicator of intracranial herniation cannot be identified. ${ }^{11,12,19,22-33,63-76}$

\section{Prognosis}

Early after head injury, the prognosis is usually uncertain. Essential factors related to outcome have been demonstrated to be coma and concomitant neurologic disorders, duration of coma, and age. Additional investigations of high predictive value among others are evoked potentials and MRI; lesions of the brainstem in particular indicate a poor prognosis.

Pituitary insufficiency is one of the often overlooked long-term sequelae after head injury that must be looked for. Weeks and months after a minimal head injury, a chronic subdural hematoma may develop, particularly in elderly and predisposed patients. ${ }^{39,77-80}$ 


\section{Long-Term Care after Head Injury}

\section{B}

Reimplantation of bone flaps after craniectomy appears advisable for protection and cosmetic reasons, particularly in patients with neurologic deficits, who are likely to fall. There is no evidence on the best timing.

Patients after craniectomy may develop secondary sequelae associated with particular pathophysiologic phenomena (e.g., increase of headache, pareses, seizures attributed to the "sinking skin flap syndrome"), mostly after ventricular drainage. Replacement of bone flaps may lead to immediate neurologic recovery. Some patients without the prospect for recovery (e.g., in a persistent vegetative state) may not benefit from reimplantation.

Long-term care is determined by the neurologic deficits and the prospect of recovery. Improvement of neurologic deficits is mostly observed within the first 2 years after the injury.

A structural adaptive neuroplasticity has been viewed as the basis of recovery, which may be supported by targeted exercise. To avoid complications (e.g., muscle contractions), rehabilitation (e.g., physiotherapy) should begin in the acute phase. Details of rehabilitation can be viewed under "Leitlinie Multiprofessionelle neurologische Rehabilitation" of the Deutsche Gesellschaft für Neurologie..$^{81-85}$

\section{Acknowledgment}

The authors are most grateful to Professor Hutchinson, Cambridge, United Kingdom, for his assistance with the preparation of this translation.

\section{References}

1 Oxford Centre for Evidence-based Medicine Levels of Evidence May 2009http://www.cebm.net/downloads/Oxford_CEBM_Levels_5.rtf

2 Nationales Programm für Versorgungs-Leitlinien. Methoden-Report Juli 2004http://www.versorgungsleitlinien. de/methodik/pdf/nplmethode.pdf

3 Rickels E, von Wild K, Wenzlaff P, Bock WJ, eds. SchädelHirn-Verletzung. Epidemiologie und Versorgung. Ergebnisse einer prospektiven Studie. Munich, Germany: Zuckschwerdt; 2006

4 Brihaye J, Frowein RA, Lindgren S, Loew F, Stroobandt G. Report on the meeting of the WFNS Neuro-Traumatology Committee. Brussels. I. Coma scaling. Acta Neurochir (Wien) 1978;40:181-186

5 Frowein RA. Classification of coma. Acta Neurochir (Wien) 1976;34(1-4):5-10

6 Gurdjian ES, Brihaye J, Christensen JC, et al. Glossary of Neurotraumatology. Acta Neurochir (Wien) (Suppl 25). Vienna, Austria: Springer; 1979

7 Lorenz R. Neurotraumatologie. Standardisierte Nomenklatur. Berlin, Germany: Springer; 1990

8 Teasdale G, Jennett B. Assessment of coma and impaired consciousness. A practical scale. Lancet 1974;2(7872):81-84
9 Teasdale G, Jennett B. Assessment and prognosis of coma after head injury. Acta Neurochir (Wien) 1976;34(1-4):45-55

10 Balestreri M, Czosnyka M, Chatfield DA, et al. Predictive value of Glasgow Coma Scale after brain trauma: change in trend over the past ten years. J Neurol Neurosurg Psychiatry 2004;75(1):161-162

11 Gabriel EJ, Ghajar J, Jagoda A, Pons PT, Scalea T, Walters BC; Brain Trauma Foundation. Guidelines for prehospital management of traumatic brain injury. J Neurotrauma 2002; 19(1):111-174

12 The Brain Trauma Foundation. The American Association of Neurological Surgeons. The Joint Section on Neurotrauma and Critical Care. Management and Prognosis of Severe Traumatic Brain Injury. 2000http://www2.braintrauma. org/guidelines/downloads/btf_guidelines_management.pdf

13 Kraus JF, Black MA, Hessol N, et al. The incidence of acute brain injury and serious impairment in a defined population. Am J Epidemiol 1984;119(2):186-201

14 Maas AI, Dearden M, Teasdale GM, et al; European Brain Injury Consortium. EBIC-guidelines for management of severe head injury in adults. Acta Neurochir (Wien) 1997; 139(4):286-294

15 Marion DW, Carlier PW. Predictive value of Glasgow Coma Scale after brain trauma. J Trauma 1994;86:89-95

16 Moskopp D, Stähle C, Wassmann H. Problems of the Glasgow Coma Scale with early intubated patients. Neurosurg Rev 1995;18(4):253-257

17 Tönnis W, Loew F. Einteilung der gedeckten Hirnschädigungen. Arztl Prax 1953;5:13-14

18 Bernard SA, Nguyen V, Cameron P, et al. Prehospital rapid sequence intubation improves functional outcome for patients with severe traumatic brain injury: a randomized controlled trial. Ann Surg 2010;252(6):959-965

19 The Brain Trauma Foundation. The American Association of Neurological Surgeons. The Joint Section on Neurotrauma and Critical Care. Guidelines for the Management of Severe Traumatic Brain Injury. 3rd ed. 2007; http://braintrauma. org/guidelines/downloads/JON_24_Supp1.pdf

20 Ghajar J. Traumatic brain injury. Lancet 2000;356 (9233):923-929

21 Karimi A, Burchardi H. Deutsche Interdisziplinäre Vereinigung für Intensivund Notfallmedizin (DIVI) Stellungnahmen, Empfehlungen zu Problemen der Intensiv- und Notfallmedizin 2004; 5. Auflage. Köln, asmuth druck + crossmedia

22 Alderson P, Roberts I. Corticosteroids for acute traumatic brain injury. Cochrane Database Syst Rev 2005;(1):CD000196

23 Schierhout G, Roberts I. Antiepileptic drugs for preventing seizure following acute traumatic brain injury. Cochrane Database Syst Rev 2012;(6):CD000173

24 Bourdeaux CP, Brown JM. Randomized controlled trial comparing the effect of $8.4 \%$ sodium bicarbonate and $5 \%$ sodium chloride on raised intracranial pressure after traumatic brain injury. Neurocrit Care 2011;15(1):42-45

25 Bulger EM, May S, Brasel KJ, et al; ROC Investigators. Out-ofhospital hypertonic resuscitation following severe traumatic brain injury: a randomized controlled trial. JAMA 2010;304(13): 1455-1464

26 Cottenceau V, Masson F, Mahamid E, et al. Comparison of effects of equiosmolar doses of mannitol and hypertonic saline on cerebral blood flow and metabolism in traumatic brain injury. J Neurotrauma 2011;28(10):2003-2012

27 Langham J, Goldfrad C, Teasdale G, Shaw D, Rowan K. Calcium channel blockers for acute traumatic brain injury. Cochrane Database Syst Rev 2004;(4):CD000565

28 Roberts I, Schierhout G, Wakai A. Mannitol for acute traumatic brain injury. Cochrane Database Syst Rev 2003;(2):CD001049 
29 Roberts I. Aminosteroids for acute traumatic brain injury. Cochrane Database Syst Rev 2000;(4):CD001257

30 Roberts I. Barbiturates for acute traumatic brain injury. Cochrane Database Syst Rev 2000;(2):CD000033

31 Roberts I, Sydenham E. Barbiturates for acute traumatic brain injury. Cochrane Database Syst Rev 2012;12(12): CD000033

32 Wakai A, McCabe A, Roberts I, Schierhout G. Mannitol for acute traumatic brain injury. Cochrane Database Syst Rev 2013;(8):CD001049

33 Willis C, Lybrand S, Bellamy N. Excitatory amino acid inhibitors for traumatic brain injury. Cochrane Database Syst Rev 2004;(1):CD003986

34 ATLS Advanced Trauma Life Support Program for Doctors. 7th ed. Chicago, IL: American College of Surgeons Committee on Trauma; 2004

35 Biberthaler P, Mussack T, Kanz KG, et al. Identification of high-risk patients after minor craniocerebral trauma. Measurement of nerve tissue protein S 100 [in German]. Unfallchirurg 2004;107(3):197-202

36 Pandor A, Harnan S, Goodacre S, Pickering A, Fitzgerald P, Rees A. Diagnostic accuracy of clinical characteristics for identifying CT abnormality after minor brain injury: a systematic review and meta-analysis. J Neurotrauma 2012;29(5):707-718

37 Mendelow AD, Teasdale G, Jennett B, Bryden J, Hessett C, Murray G. Risks of intracranial haematoma in head injured adults. Br Med J (Clin Res Ed) 1983;287 (6400):1173-1176

38 Vos PE, Alekseenko Y, Battistin L, et al. Mild traumatic brain injury. In: Hughes RA, Brainin M, Gilhus NE, eds. European Handbook of Neurological Management. Oxford, UK: Blackwell Publishing; 2006

39 Firsching R, Woischneck D, Klein S, Reissberg S, Döhring W, Peters B. Classification of severe head injury based on magnetic resonance imaging. Acta Neurochir (Wien) 2001;143(3):263-271

40 Bullock MR, Chesnut R, Ghajar J, et al. Guidelines for the surgical management of traumatic brain injury. Neurosurgery 2006;58(Suppl 3):S1-3

41 Firsching R, Heimann M, Frowein RA. Early dynamics of acute extradural and subdural hematomas. Neurol Res 1997;19(3):257-260

42 Fernandez R, Firsching R, Lobato R, et al. Guidelines for treatment of head injury in adults. Zentralbl Neurochir 1997;58(2):72-74

43 Rotondo MF, Schwab CW, McGonigal MD, et al. 'Damage control': an approach for improved survival in exsanguinating penetrating abdominal injury. J Trauma 1993;35(3): 375-382; discussion 382-383

44 Cooper DJ, Rosenfeld JV, Murray L, et al; DECRA Trial Investigators; Australian and New Zealand Intensive Care Society Clinical Trials Group. Decompressive craniectomy in diffuse traumatic brain injury. N Engl J Med 2011;364(16):1493-1502

45 Qiu W, Guo C, Shen H, et al. Effects of unilateral decompressive craniectomy on patients with unilateral acute post-traumatic brain swelling after severe traumatic brain injury. Crit Care 2009;13(6):R185

46 Sahuquillo J, Arikan F. Decompressive craniectomy for the treatment of refractory high intracranial pressure in traumatic brain injury. Cochrane Database Syst Rev 2006;((1): CD003983

47 Balestreri M, Czosnyka M, Hutchinson P, et al. Impact of intracranial pressure and cerebral perfusion pressure on severe disability and mortality after head injury. Neurocrit Care 2006;4(1):8-13
48 Blaha M, Lazar D, Winn RH, Ghatan S. Hemorrhagic complications of intracranial pressure monitors in children. Pediatr Neurosurg 2003;39(1):27-31

49 Bullock R, Chesnut RM, Clifton G, et al; Brain Trauma Foundation. Guidelines for the management of severe head injury. Eur J Emerg Med 1996;3(2):109-127

50 Chesnut RM, Temkin N, Carney N, et al; Global Neurotrauma Research Group. A trial of intracranial-pressure monitoring in traumatic brain injury. N Engl J Med 2012; 367(26):2471-2481

51 Fakhry SM, Trask AL, Waller MA, Watts DD; IRTC Neurotrauma Task Force. Management of brain-injured patients by an evidence-based medicine protocol improves outcomes and decreases hospital charges. J Trauma 2004; 56(3):492-499, discussion 499-500

52 Firsching RJ, Voellger B. Evidence-based indications for ICP recording after head injury. A review. Cent Eur Neurosurg 2010;71(3):134-137

53 Forsyth RJ, Baxter P, Elliott T. Routine intracranial pressure monitoring in acute coma. Cochrane Database Syst Rev 2001; (3): CD002043

54 Forsyth RJ, Wolny S, Rodrigues B. Routine intracranial pressure monitoring in acute coma. Cochrane Database Syst Rev 2010;(2):CD002043

55 Hiler M, Czosnyka M, Hutchinson P, et al. Predictive value of initial computerized tomography scan, intracranial pressure, and state of autoregulation in patients with traumatic brain injury. J Neurosurg 2006;104(5):731-737

56 Lane PL, Skoretz TG, Doig G, Girotti MJ. Intracranial pressure monitoring and outcomes after traumatic brain injury. Can J Surg 2000;43(6):442-448

57 Mauritz W, Janciak I, Wilbacher I, Rusnak M; Australian Severe TBI Study Investigators. Severe traumatic brain injury in Austria IV: intensive care management. Wien Klin Wochenschr 2007;119(1-2):46-55

58 Palmer S, Bader MK, Qureshi A, et al; Americans Associations for Neurologic Surgeons. The impact on outcomes in a community hospital setting of using the AANS traumatic brain injury guidelines. J Trauma 2001;50(4):657-664

59 Plötz FB, Kneyber M, van Heerde M, Markhorst D. Traumatic pediatric brain injury and intracranial pressure monitoring: does it really improve outcome? Intensive Care Med 2007;33(9):1675

60 Shafi S, Diaz-Arrastia R, Madden C, Gentilello L. Intracranial pressure monitoring in brain-injured patients is associated with worsening of survival. J Trauma 2008; 64(2):335-340

61 Jaeger M, Schuhmann MU, Soehle M, Meixensberger J. Continuous assessment of cerebrovascular autoregulation after traumatic brain injury using brain tissue oxygen pressure reactivity. Crit Care Med 2006;34(6): $1783-1788$

62 Steiner LA, Czosnyka M, Piechnik SK, et al. Continuous monitoring of cerebrovascular pressure reactivity allows determination of optimal cerebral perfusion pressure in patients with traumatic brain injury. Crit Care Med 2002; 30(4):733-738

63 Adelson PD, Bratton SL, Carney NA, et al. Guidelines for the acute medical management of severe traumatic brain injury in infants, children and adolescents. Chapter 17. Critical pathway for the treatment of established intracranial hypertension in pediatric traumatic brain injury. Pediatr Crit Care Med 2003; (3 Suppl):S65-67

64 Alderson P, Gadkary C, Signorini DF. Therapeutic hypothermia for head injury. Cochrane Database Syst Rev 2004;4(4):CD001048. Doi: 10.1002/14651858.CD001048. pub2 
65 Bennett M, Heard R. Hyperbaric oxygen therapy for multiple sclerosis. Cochrane Database Syst Rev 2004;1(1): CD003057. Doi: 10.1002/14651858.CD003057.pub2

66 Brodie HA. Prophylactic antibiotics for posttraumatic cerebrospinal fluid fistulae. A meta-analysis. Arch Otolaryngol Head Neck Surg 1997;123(7):749-752

67 Chang BS, Lowenstein DH; Quality Standards Subcommittee of the American Academy of Neurology. Practice parameter: antiepileptic drug prophylaxis in severe traumatic brain injury: report of the Quality Standards Subcommittee of the American Academy of Neurology. Neurology 2003;60(1):10-16

68 Clifton GL, Miller ER, Choi SC, et al. Lack of effect of induction of hypothermia after acute brain injury. N Engl J Med 2001;344(8):556-563

69 Roberts I, Yates D, Sandercock P, et al; CRASH trial collaborators. Effect of intravenous corticosteroids on death within 14 days in 10008 adults with clinically significant head injury (MRC CRASH trial): randomised placebo-controlled trial. Lancet 2004;364(9442):1321-1328

70 Edwards P, Arango M, Balica L, et al. Final results of MRC CRASH, a randomised placebo-controlled trial of intravenous corticosteroid in adults with head injury-outcomes at 6 months. Lancet 2005;365(9475):1957-1959

71 Georgiou AP, Manara AR. Role of therapeutic hypothermia in improving outcome after traumatic brain injury: a systematic review. Br J Anaesth 2013;110(3): 357-367

72 Harris OA, Colford JM Jr, Good MC, Matz PG. The role of hypothermia in the management of severe brain injury: a meta-analysis. Arch Neurol 2002;59(7):1077-1083

73 Narayan RK, Maas AI, Marshall LF, Servadei F, Skolnick BE, Tillinger MN; rFVIIa Traumatic ICH Study Group. Recombinant factor VIIA in traumatic intracerebral hemorrhage: results of a dose-escalation clinical trial. Neurosurgery 2008;62(4):776-786; discussion 786-788

74 Piek J, Chesnut RM, Marshall LF, et al. Extracranial complications of severe head injury. J Neurosurg 1992;77(6): 901-907
75 Villalobos T, Arango C, Kubilis P, Rathore M. Antibiotic prophylaxis after basilar skull fractures: a meta-analysis. Clin Infect Dis 1998;27(2):364-369

76 Yanagawa T, Bunn F, Roberts I, Wentz R, Pierro A. Nutritional support for head-injured patients. Cochrane Database Syst Rev 2002;(3):CD:001530

77 Kelly DF, Gonzalo IT, Cohan P, Berman N, Swerdloff R, Wang C. Hypopituitarism following traumatic brain injury and aneurysmal subarachnoid hemorrhage: a preliminary report. J Neurosurg 2000;93(5):743-752

78 Lieberman SA, Oberoi AL, Gilkison CR, Masel BE, Urban RJ. Prevalence of neuroendocrine dysfunction in patients recovering from traumatic brain injury. J Clin Endocrinol Metab 2001;86(6):2752-2756

79 Schneider HJ, Stalla GK, Buchfelder M. Expert meeting: hypopituitarism after traumatic brain injury and subarachnoid haemorrhage. Acta Neurochir (Wien) 2006; 148(4):449-456

80 Frowein RA, Firsching R. Classification of head injury. In: Vinken PJ, Bruyn GW, eds. Handbook of Clinical Neurology. Vol. 13. Amsterdam, Netherlands: Elsevier; 1990: 101-122

81 Akins PT, Guppy KH. Sinking skin flaps, paradoxical herniation, and external brain tamponade: a review of decompressive craniectomy management. Neurocrit Care 2008; 9(2):269-276

82 Archavlis E, Carvi Y Nievas M. The impact of timing of cranioplasty in patients with large cranial defects after decompressive hemicraniectomy. Acta Neurochir (Wien) 2012;154(6):1055-1062

83 Bijlenga P, Zumofen D, Yilmaz H, Creisson E, de Tribolet N. Orthostatic mesodiencephalic dysfunction after decompressive craniectomy. J Neurol Neurosurg Psychiatry 2007;78(4):430-433

84 Frowein RA, Firsching R. Personality after head injury. Acta Neurochir Suppl (Wien) 1988;44(Suppl):70-73

85 Frowein RA, Terhaag D, auf der Haar K, Richard KE, Firsching R. Rehabilitation after severe head injury. Acta Neurochir Suppl (Wien) 1992;55:72-74 